\title{
Interactive Research on WeChat Public Platform and Mobile Library Application in Colleges and Universities
}

\author{
Liang yu \\ Chongqing Medical And Pharmaceutical College, ChongQing 401331, China
}

Keywords: Colleges and universities; WeChat public platform; Mobile library; Interaction

\begin{abstract}
With the continuous development of modern information technology, college reading platform model is also in constant change. From the perspective of the existing application software, system application measures and application survey structure of the whole service status quo and problems both need to carry on the comprehensive education development implementation according to the existing WeChat platform, and in accordance with relevant standards, achieve the application analytical analysis on basis of phase structure and to improve discuss effect.

In face of modern education development form, different structure mode mainly focuses on teaching form content applications, and through the corresponding infrastructure education promotion, promotes good construction for mobile network platform in order to improve the application analysis on the whole interactive channels and realize the rationalization of whole education structure. A brief analysis and discussion of modern university WeChat public platform and the interactive application of mobile library is made below.
\end{abstract}

\section{THE MEANING OF WECHAT PUBLIC PLATFORM}

From the gradual improvement of microblog era, people's social information communication form is also in constant development, in which, combined with corresponding structure foundation, realize the safe use of characteristics and different characteristics, and also can better meet the needs of different users demand. For the existing communication social tools, information management is available from the registered user information for the use on overall strategy. On the function analysis of WeChat public platform, determine further from the use of the existing mobile clients, and combine with the corresponding system to improve the role application under different times.

For WeChat public platform, the actual construction of function module, make mobile optimization with main mobile application rules to improve the application analysis of the whole interaction. Take comprehensive service system as a marketing purpose, and apply it to approach multidisciplinary facilities to get application analysis, and achieve the specification application of modern teaching library mode.

\section{THE ADVANTAGE ANALYSIS OF WECHAT PUBLIC PLATFORM FOR MOBILE LIBRARY READING}

As microblog form's gradual perfection, in reality applications of mobile terminal, different application mode can use the existing terminal structures to do mobile services and effectively improve user experience effect. For mobile services in the business and the independent advantages expanded are mainly focused on the following points.

\section{A. Low construction cost}

For modern use devices' terminal applications basis, there are different library application forms and book APP analysis can be made from different angles combined with corresponding technical means to realize the regulation analysis for service supply concept. Compared with traditional printed book forms, modern database form provides more comprehensive information resources for readers. On application, it can be more effective to ensure the validity of information system. On a finer application of versions, the use version of mobile terminal also needs to combine with the actual user usage, selects rational application form to improve the structure application of the overall. 
In the process, WeChat public platform can effectively ensure the application analysis on library in the related application information, and in accordance with the corresponding information technology, implement the effective control of information data. Make applications demand analysis in system development field and in updated versions, including different WeChat information, the management application of the library, etc. can be more to improve the effective service experience.

\section{B. WeChat's large user base}

Since WeChat exit, the users increase rapidly. Global APP application software also has a great improvement. In mobile phone application software APPs, WeChat users scale is very large, and later growth space and application concept have greatly promoted the experience of Internet users in the network service. Due to the user basis and high use viscosity, in the process of library independent development, apply effective public development form to more effectively promote the effective application of the basic platform. Reasonable openness of modern mobile libraries can effectively ensure students' dynamic grasp of library information.

\section{Stronger interaction}

In microblog and WeChat viscosity and communication sense application, in order to ensure WeChat's closed loop exchange analysis in illicit close space, achieve the user's application and influence factors discussion with the greatest characteristics, and better realize synchronous online concept of images and usage. Make effective information communication and the role also can satisfy the transmission way of basic information. In modern user's distribution form analysis, combination of pronunciation, words, pictures and other ways is used to communicate relevant information. In mutual interaction, public account also can make better specific reading frequency statistics in order to realize the use of different function.

\section{More function of promotion benefits}

From the actual exchange perspective of WeChat platform, different communication and learning entertainment platforms can integrate through mass push and information use law because of the complexity of its function on the basis of not only satisfying basic communication, but also mass texting push due to its basic information goal is more widely. At the same time, when the user has carried out card information binding, it is more effective to connect the information for communication in order to promote the adjustment of the public platform on the structure application. Adjustments in library mobile service and function application can be made through a third party response and docking to realize its overall promotion use on human and application time. The process also greatly improves the experience in the process of users in actual use. The existing library mobile service function can make integrate adjustment from the corresponding thought train.

\section{THE APPLICATION STATUS OF LIBRARY WECHAT PLATFORM}

Since WeChat's official launch, people's attention to WeChat is in continuous improvement. How to apply WeChat public platform for attention and use correlation function can be processed integrative from the following several points. The search analysis of key information can make integration analysis from the following several points. Platform public information utilization analysis can make integration analysis from the following several points.

\section{A. The utilization of WeChat public platform in service field}

WeChat public platform, as a new type of information traffic tool, in application, through mutual connection between data, ensures the software communication in chat communication information and its function can be more effectively promoted and to be used widely in information field. Preliminary application in various stages can make integration processing from the existing libraries colleges and universities registry platform, and analyze the utilization integration of whole WeChat platform information in the process.

\section{B. Library public platform's application balance}

WeChat platform application balance in campus library can be analyzed from the existing book platform form. Our country's western region action mechanism analysis, compared to other 
environment analysis, is able to better satisfy different information use in the field for the whole library utilization form, etc.

\section{Library public account's user name confusion}

In the process of adjusting difference, the regulation of a lot of public library registrations in application library, user application nicknames and fuzzy function adjustment need integrate analysis from multiple fields, and in accordance with the corresponding structure foundation, achieve integration of library user information. In the course of actual use, such as Hangzhou library's public accounts, at the time of registration, there were two confusing officials, and caused some mistakes in actual use, which affected the actual use security.

\section{Service content and function provided are not perfect enough}

In modern WeChat platform library application construction, its short construction time led to many problems, therefore, for the whole safe use specification, the current book YunYing public platform can be used for information integration processing, and realizes the application of the whole on the basis of the corresponding service experience. But in nowadays WeChat public application, its basic information service system construction is not perfect, leading to bigger services vulnerabilities in actual application, thus affecting normal reading.

\section{DEVELOPMENT DIRECTION ANALYSIS OF MODERN UNIVERSITY LIBRARIES AND WECHAT PLATFORMS}

In modern WeChat platform and user experience system construction, in order to promote different connection modes and application channels' user service analysis, in combination with the existing rules to adjust, and in accordance with the users structure use in WeChat application platform. From the present library's particularity and application basis, explore public platform establishment under different social public value to improve the promotion of social value and application efficiency. For different problems and use direction, we analyze from the present social application attitudes. Make appropriate adjustments from the following aspects to better promote the overall university library application platform development direction construction.

\section{A. Improve the platform attention to expand user groups}

In modern information platform construction, combine the adjustment of WeChat platform focused attention to overall user community, and realize execution adjustment of mobile server on the basis of corresponding library application information. And in the process, combined with user community awareness of platform, better adapt to the normal development of modern society.

\section{B. Pay attention to the secondary open platform}

In modern WeChat platform construction, make integration construction from the open public platform for interface technology, and in accordance with the corresponding public account and actual demand server system construction, and improve the effective construction of overall WeChat public account. On the secondary drive of functional use, take actual and applicable disconnecting operations as the root of subsequent development, and make further consolidation process, improve the overall management system and database information, and accelerate the adjustment of system integration function. For user interest in the field of demand and application, adjust the reader's reliance on library and user public account.

\section{Ensure user experience quality}

For WeChat public use, combine with the user's attention to overall reason and information on the platform of information and advertising, and ensure information adjustment in actual use process to overall structure in the application range. Combined with high quality service and experience with corresponding content and rich effect, the promotion of the quality of public service can be combined with the user quality to push on the acute content in the process. In actual service, strengthen the real-name registration of users on the use information. 


\section{CONCLUSION}

In general, with gradual mature of modern information technology, mobile service field application can be combined with the extension of mobile services to promote the use adjustment of different areas, combine with the corresponding information basis services, and ensure the business investment and security basis supply. And combine with the corresponding management system to realize the popularization and application of basic information and protect information accuracy in public actual use, and application effect of library mobile reading.

\section{REFERENCE}

[1] Zhang Qiu, Yang Ling, Wang Man. The present development situation and countermeasures of library WeChat public platform service in university [J]. Journal of Library Construction, 2014, (2) : 61-65,69.

[2] Bai Mingfeng, Kuang Huihua. Application and reference for mobile information service in university library of light application mode----based on university library WeChat account analysis [J]. Journal of Public Information Work, 2014, (4) : 78-81.

[3] Zhang Changheng, Huang Fang. University library APP technology by using WeChat public platform construction [J]. Journal of Library Intelligence, 2015, (4) : 37-43.

[4] Wu Longlong. Library WeChat public platform service present situation investigation and analysis in university [J]. Digital Library BBS, 2014, (4): 56-60.

[5] Cai Hongqi. Mobile library information service innovation under WeChat public platform [J]. Library Journal, 2016, (2) : 78-80.

[6] Lu Jiansong. University mobile library service study based on WeChat public platform [J]. Journal of Modern Marketing, 2016, (3) : 144.

[7] Zeng Runxi, Yang Xixi. Mobile context knowledge dissemination platform management effect study----based on the country's 406 university library WeChat public survey [J]. Library Journal, 2016, (7) : 79-84105.

[8] Li Feng, Wei Hong, Long Ruolan. The present situation and strategy research of library WeChat public platform use in mobile Internet era [J]. Journal of University Library Work, 2014, (6) : 58-60. 